carrier of a number of serious diseases in sheep on hill farms. Dr. A. Milne described the general features in the ecology of this tick. It is widely spread throughout the hill sheep-farming areas of Great Britain, but occurs only in those localities where the pastures are rough, with a thick layer or 'mat' of dead and dying vegetation at the base of the herbage. The humidity in this mat is always about 100 per cent, and it appears to be this high humidity which is the limiting factor in the distribution of the tick. This is not surprising when it is realized that the sheep tick is not resistant to desiccation, and yet during its life-cycle of two to three years it spends only about six weeks in feeding on its host. For the rest of its life it is lying inactive in the moist mat or is at the tips of the grass stems waiting for a passing host. In most of the country there is only one period, in the late spring and early summer, during which the ticks are active in this way. But there are some localities, notably in the west of England, where there is a second peak of activity in the autumn. (An apparent peak in the summer which has been described in Wales is spurious and has been wrongly inferred from the gradual rise in the numbers of ticks upon stock introduced to infested pastures.) Pasture improvement, with the elimination of the humid 'mat', will effectively eradicate the sheep tick-though this is seldom economically practicable on the hill farms.

Dr. J. Allan Campbell described his detailed studies of the developmental cycle of the sheep tick in Nature. The temperature in the natural environment ranges between $-2^{\circ} \mathrm{C}$. and $+15^{\circ} \mathrm{C}$. At these temperatures development and egg-laying proceed at much slower rates than has been inferred from studies in the laboratory. In the normal cycle the tick at each stage of its development feeds in the spring or early summer, moults or oviposits during the summer, and overwinters in the unfed state. But there is a second cycle in which the ticks feed in the autumn, pass the winter in the egg or in the engorged state, and hatch or moult in the spring. It is these two populations, between which there seems to be little interchange, which are responsible for the two peaks of activity in the spring and in the autumn. The threshold temperature for development of the egg is $7^{\circ} \mathrm{C}$.; but the eggs laid by the ticks of the autumn feeding cycle will not develop, even at $10-20^{\circ} \mathrm{C}$., until they have been exposed to severe cold for a good many weeks.

The physiology of the sheep tick, as described by Dr. A. D. Lees, goes far towards explaining the observations made on its ecology. When compared with a series of other ticks, 1xodes ricinus has a cuticular wax of very poor waterproofing powers, and it is this which limits its distribution. The closely related dog tick Ixodes canisuga, which has a cuticular wax of higher melting point, is alone able to survive in the kennels of the sheep dogs, although both species are picked up by them. So long as Ixodes remains in a nearly saturated atmosphere, it can absorb water vapour actively through its cuticle and maintain its water content. When it becomes active in the spring, the unfed tick shows a negative response to gravity and an avoidance of high humidity which lead it to the tips of the grasses, where its sensitive responses to vibration, to passing shadows and to eddies of warm air and smell enable it to cling to a passing host. The unfed tick at each stage of its life-cycle can remain latent in the humid mat for many months. The length of time it can resist starvation is determined by its reserves of fat carried over from the previous stage. After becoming active and resting for some time at the tips of the grasses, it loses moisture and it then returns to the mat to restore its water content by the active uptake of water vapour. 'This form of activity is necessary if the tick is to secure a meal to enable it to grow or reproduce. But it soon exhausts the limited reserves of fat, and the active tick dies of starvation far sooner than the more sluggish individual which remains dormant at the base of the vegetation.

In closing the discussion, Dr. Wigglesworth said that the sheep tick problem was chosen because it illustrates particularly well the way in which a knowledge of the detailed physiology of a pest enables the applied biologist to think clearly and rationally about it and to see his problems in a new light. That is part of the debt of applied entomology to insect physiology. But there is a debt of perhaps even greater magnitude in the other direction. Many of the most important discoveries in insect physiology, and indeed in biology in general, have resulted from the intellectual stimulus of contact with some practical problem.

\section{BUILDING RESEARCH CONGRESS, 1951}

7 HE Building Research Congress held in London during September 11-20 was the outcome of co-operation between some two-dozen professional institutions and trade federations interested in build. ing and civil engineering construction, the Depart. ment of Scientific and Industrial Research and the Ministry of Works. As the first of its kind ever to be held, it aroused much interest both in Great Britain and overseas, and among its 1,400 members were representatives of more than fifty countries; of the eighty-eight papers presented forty-five were by authors from outside Great Britain. The enthusiasm with which the Congress was greeted was a clear indication of the need for such a conference, and the large attendance from abroad was a tribute to the regard in which the pioneer work of Great Britain in this field is held. The Congress, the organization of which was largely undertaken by the Building Research Station of the Department of Scientific and Industrial Research, met under the presidency of Lord Samuel.

The opening session, held at the Institution of Civil Engineers on the morning of September 11, was the occasion of the first of Lord Samuel's thoughtprovoking contributions. He directed attention to the effect environment - man-made as well as naturalhas had on individuals and pointed out the effect that building research could therefore have on individual and national life. Dr. F. M. Lea, director of building research in the Department of Scientific and Industrial Research, traced the growth of organized building research and made a plea for still closer co-operation of industry in the application of its results. In the afternoon members were the guests of the Government at a reception at Lancaster House, and later, under the auspices of the Parliamentary and Scientific Committee, visited the new House of Commons Chamber and other parts of the Palace of Westminster.

For the technical sessions, the Congress was organized in three divisions, dealing with the engin- 
eering and constructional problems, with building materials, and with the factors affecting the use of buildings. For most of the period of the Congress there were thus five concurrent sessions; the papers, all of which had been specifically invited, had been circulated before the Congress and were therefore only briefly introduced, so that most of the time was available for discussions, which were at all times lively.

The first two sessions in Division 1 were devoted to papers dealing with the influence of mechanization and prefabrication on techniques and cost of building. After a general review had been given by $\mathrm{R}$. Fitzmaurice (Great Britain), there were papers from Holland, the United States and France, on the latest developments in the building of dwellings in these countries. It was apparent that there is still a good deal of work in progress on non-traditional construction. Research into the use of mechanical aids in building operations was covered in a paper dealing with work in Great Britain, and it was pointed out that the full application of aids of this sort has yet to be effected. The last paper in this group was from Switzerland and dealt with the changes which new building methods bring into design and drawingoffice procedure. Perhaps the main feature brought out in the discussion of this group of papers was the slow effect innovations have on the structure and techniques of so traditional an industry.

Three sessions were then devoted to the influence of modern research on structural design, in which a general review paper was given by Prof. G. Wastlund (Sweden). A group of four papers dealt with research on the use of concrete in structures, and considerable interest was aroused particularly in the two papers in this group which dealt with pre-stressed concrete and the design and use of thin concrete shells. A further four papers dealt with research into the use of steel in structures; and these papers covered such points as the way in which research has been helping the designer, research on structural steelwork particularly with reference to the behaviour of structures beyond the elastic range, and the application of welding in steel structures. A third session in this group was devoted to timber and light alloys; in this session there was a paper dealing with the modern development of the use of glued laminated timber as a structural material.

The final two sessions in Division 1 were concerned with the influence of modern soil studies on the design and construction of foundations, and it was fitting that the introductory paper should have been written by Prof. K. Terzaghi (United States). The other papers presented were drawn from the United States, Great Britain, Canada and Holland.

The proceedings of Division 2 opened with an introductory paper by Dr. T. W. Parker, deputy director of building research, Department of Scientific and Industrial Research, on general trends in research on building materials, in which reference was made to the importance of pursuing an adequate measure of fundamental research, despite the pressing demands of day-to-day technical problems, and to the need for the co-ordination of information on materials so that each may be used to the best advantage to meet the overall functional requirements of the building. The remainder of the proceedings were concerned with papers from Britain, Canada, Australia, South Africa, the United States, France, Holland and Germany, on varied aspects of research on the production, properties or utilization of the main building materials.
Four papers on the weathering and durability of building materials generally and another on the durability of concrete in engineering structures demonstrated the complexity of a subject that covered the whole range of building materials under temperate, tropical and sub-arctic conditions, and revealed much common ground of observation and experience.

Papers on burnt-clay products described developments in manufacturing processes induced in some measure by the need for economy in the use of both fuel and labour, and showed evidence of the growing recognition by the industry of the part that new fundamental knowledge of the nature of clay can play in guiding technical control of the operations. A survey was presented of the work that has been done, mainly in Great Britain, on the structural performance of burnt-clay products in respect of strength, resistance to rain penetration, fire resistance, and other functional requirements-investigations that provide a sound basis for framing codes of practice and building by-laws.

Contributions from the United States, Britain and France on the quality control of concrete on building sites showed that substantial advantages can be gained by the adoption of an organized system of control. Concrete of the quality specified in a contract can be secured with a reduced consumption of cement. Appropriate change in the conventional form of specification would provide an incentive to take economic advantage of the use of quality-control methods.

The economic and functional merits of light-weight concretes were discussed, and a review was presented on the effects of curing concrete at elevated temperature, each with comments on the directions in which there is still scope for fundamental and technical investigation.

Two papers dealt with the utilization of building stone with particular reference to means for reducing costs. One referred to the adoption of a restricted range of standard sizes of block stone in the French Standard B10-001 and described the construction and performance of the machines that have been developed in France for winning the stone from the quarry face and for its subsequent preparation. The other paper, based on a recent survey, set out the present differences in the cost of building houses in stone and in brick in the more important stone-producing districts of England and Scotland, and suggested ways in which the cost of building houses in stone might be reduced.

A contribution on the burning and hydration of lime described physicochemical studies that have been undertaken in South Africa with the object of explaining and eliminating building defects attributed to unsoundness in certain magnesium limes used there. Other papers dealt with the production, properties and uses of ealcium sulphate plasters, with paint application, and with developments in limewash and cement paints.

The proceedings of Division 2 concluded with the presentation of three papers on timber technology. One, on the resistance to wear of timber flooring, described the development of testing equipment to reproduce qualitatively and quantitatively the wear effects observed in service ; another described investigations on the use of plywood as a building material; and the third, investigations on the durability and preservation of timber.

Division 3 concerned light, heat and sound in buildings, and design research on three types of 
buildings-hospitals, factories and schools. Papers had been invited from authors in Great Britain, United States, Sweden, Holland, Germany, Austria, South Africa, Australia, Switzerland and France.

In the group of papers on lighting research and its application to building problems, the four main aspects of the problem were each treated in turn. First there was a group of papers dealing with the brightness pattern of the work (meaning the particular object of attention) and its surroundings. Then came a group of papers dealing with sources of artificial light, where the difficulty is to get desired levels of lighting on the work and elsewhere without these sources send. ing too much light directly into the observer's eyes. The same sort of problem was stressed in the group of papers on the use of daylight, where the window is the source of light. The final group of papers was on the use of colour, by which one factor in brightness is controlled. Papers in this group on lighting made their contributions through the study of principles, of measurement and of subjective investigation, all being applied to the buildings themselves.

In heating, the range of the subject-matter discussed was wide both in methods and geography. There were papers on laboratory and analogue studies, on full-scale experiments, and on the problems presented by the range of climates from temperate to tropical. The effect of building design, and especially of thermal capacity, was found as an influence in most of the papers and discussions, especially in relation to the problems of non-steady heating. These same factors appeared also in the consideration of tropical buildings where thermal capacity is one of the main design factors by which tolerable conditions can be obtained when expensive cooling equipment cannot be used. In the session devoted to the design of heating plant, an interesting recent technique reported was the use of high-pressure hot-water sys. tems using temperatures as high as $350^{\circ} \mathrm{F} .\left(176 \cdot 7^{\circ} \mathrm{C}\right.$.) with consequent savings in size and cost of heating services.

The group of papers on sound were centred round the topical acoustical problems associated with auditoria and broadcasting studios. Once again, the range of matter discussed was wide, and extended from the contribution which recent theoretical developments in acoustics may be able to make to design as compared with older geometrical and statistical methods, to the consideration of the very large halls which are a feature of United States auditoria and which seat upwards of five thousand people. The particular problems of broadcasting studios were discussed in papers from Great Britain and Switzerland, as were open-air auditoria, general-purpose halls and halls designed specifically for musical purposes.

Towards the end of the Congress three sessions in Division 3 were devoted to the study of three particular types of building. One session was devoted each to hospitals, factories and schools. This application of building research is a recent development, and it is perhaps surprising to find the strict way in which experimental techniques can be, and are being, used in architectural design research. This was most strikingly demonstrated in the hospital section, where detailed observations of the use and administration of wards have led to a new thesis in planning which is now to be the subject of full-scale experiment. The schools section revealed an equally interesting innovation in the use of large-scale industrial development methods for the production of high-quality schools of various types. The section on factories was notable for the stress laid on the contribution the architect can make not only to the appearance of the building itself, but also to the detailed planning and arrangement of its interior in terms of the work to be done inside the building.

It is appropriate that the closing meetings, on September 20, should have taken place in the Royal Festival Hall, which is itself an outstanding conterm. porary example of the application of building research. No formal summing-up of the Congress was attempted; but at the morning session a number of members from overseas gave their impressions of the effect the Congress might have on the problems of their countries. Several of those who spoke took the opportunity of suggesting that smaller and more specialized con. ferences might be arranged in the future and then followed by another comprehensive congress after a period of several years. In the afternoon, Sir Ben Lockspeiser, secretary of the Department of Scientific and Industrial Research, gave an address in which he directed attention to the urgent need for the fuller application of the results of the work of men of science in this field.

\section{LOCALIZATION OF GUSTATORY AND OLFACTORY ENZYMES IN THE RABBIT, AND THE PROBLEMS OF TASTE AND SMELL}

\author{
By A. F. BARADI and DR. G. H. BOURNE \\ Department of Histology, London Hospital Medical \\ College, E.I
}

T has been shown ${ }^{2}$ that alkaline glycerophosphatase is localized in the gustatory regions of the tongue in a number of mammals (bat, rabbit and man) and in the olfactory mucosa of the rabbit. Since then, Baradi and Bourne ${ }^{8}$ have shown that a simple esterase is present in the taste buds and epithelium of the papilla foliata of the rabbit, and that the histochemical reaction for this enzyme was inhibited by the addition of quinine to the substrate mixture and the glycerophosphatase reaction by vanillin.

In addition to these two enzymes, we have found that enzymes are present in the papilla foliata and the olfactory mucosa of the rabbit which split various substrates, such as hexose diphosphate, adenosine triphosphate, muscle adenylic acid (5-nucleotidase, Reis $^{3}$ ), yeast adenylic acid (3-nucleotidase), nucleic acid (probably ribonuclease), long-chain fatty acids (lipase), alpha-glycerophosphate at $p \mathrm{H} \quad 3-5$ (acid phosphatase). The distribution of these enzymes in the papilla foliata is shown in Fig. 1. In general, one can say that all the enzymes are located in the epithelium lining the folds between the papillæ, although some are present in addition in the neighbouring epithelium. Acid phosphatase is present in only small amounts at the bases of the papillæ; ribonuclease is present only in the epithelium immediately overlying the taste buds; esterase and acid phosphatase are present in taste buds and in Ebner's glands; and the enzymes which split yeast and muscle adenylic acid appear to be present in all nuclei in the preparations, as well as in the cyto. plasm of superficial epithelial cells. 